\title{
THEORETICAL AND METHODOLOGICAL FOUNDATIONS OF THE REGIONAL SOCIAL-ECOLOGICAL-ECONOMIC SYSTEM POLYFACTOR MONITORING
}

\author{
Yandarbayeva Louisa Abdurashidovna ${ }^{1}$, Adzhieva Anna Yurevna ${ }^{2}$, Tsurova Liza Akhmetovna ${ }^{3}$, Misakov \\ Anzor Valerievich ${ }^{4}$, Molamusov Zalim Khashaovich ${ }^{5}$ \\ ${ }^{1}$ Candidate of Science (Economics), Associate Professor of the Department of Management and State \\ Municipal Management of the FSBEI of HE "Chechen State University" \\ ${ }^{2}$ Candidate of Science (Economics), Associate Professor of Monetary Circulation and Credit Department at \\ FSBEI of HE "Kuban State Agrarian University" \\ ${ }^{3}$ Ph.D. in Economics, the Head of Finance and Credit Department at FSBEI of HE "Ingush State University" \\ ${ }^{4}$ Candidate of Science (Economics), Senior Researcher of "Innovation Process Economics" department at the \\ Institute of Informatics and Regional Administration Problems of the FSBSI FSC "Kabardino-Balkarian \\ Scientific Center of the Russian Academy of Sciences" \\ ${ }^{5}$ Candidate of Economic Sciences, Associate Professor of Trade and Public Catering Department at the \\ Krasnodar Branch of the Russian Economic University named after G.V. Plekhanov
}

\begin{abstract}
The article analyzed the problems of stable and balanced social and economic development in the depressed republics of the North Caucasus, the basic approaches to the concepts of growth and development, the sustainable growth, the sustainable development and the balanced development were considered. It was justified that in order to obtain an integrated assessment of social-ecological and economic development factor and condition effectiveness of the region in order to ensure the end results, it is advisable to apply the multifactorial monitoring of regional economic system state management within increasing competition conditions. They proposed the polyfactorial monitoring modification of the state administration by the territories, which, unlike the known ones, also allows to consider the ecological component.
\end{abstract}

Keywords: economic crisis, growth and development, sustainable growth and sustainable development, balanced development, polyfactorial monitoring, public administration, regional economic system.

\section{INTRODUCTION}

Over the past ten years, two global economic crises occurred, which affected the national economy of Russian Federation. Besides, the sanctions of the Western powers and the United States also had a negative impact on the economies of the regions. The management of many regions has no modern tools to diagnose and analyze the economic situation of a territory, which requires the development of an effective apparatus for multifactorial monitoring of state management by the regions.

\section{METHODOLOGY OF THE STUDY}

The subject of the study is the problems of a stable and balanced development provision for regional socialecological and economic systems. Various methods of economic research have been applied: comparative and logical analysis, functional and systemic approach, correlation-regression analysis, and multifactor monitoring.

\section{RESULTS OF THE STUDY}

1. The genesis of the approaches to assess a sustainable economic development and growth

The key trends of a modern state strategic development are oriented to a long-term development and proceed from the assumption that a sustainable economic development and economic growth are conditioned mainly by the achievements in the field of health care, education and living standards. In most works, a sustainable economic growth is seen as a fundamental economic problem, thus the conclusions are drawn about the level and the effectiveness of the strategic management system, the degree of national economy development, the 
level of population welfare and life quality [4, 7]. At that, if we consider the evolution of crises, we can see the absence of a linear relationship between the indicators of economic growth and the level of profitability and the welfare of citizens, even in the most developed countries. This is confirmed by long-term results of international researchers. Thus, in particular, the UN reports explicitly state that the rate of return can not be regarded as the determining one when the level of development is analyzed, because this indicator can not be universal for a simple reason. It has many shortcomings. In particular, the profitability indicator ignores the inequality of distribution and does not take into account the volatility of the current production.

The Human Development Report of 2010 indicates that the analysis revealed the weakening of the relationship between economic growth and non-income-measured development aspects. In part, this is due to the fact that after a while, most innovations become more accessible to less developed countries, and as the result their level of development should be determined more by the way they use new ideas than the total costs of innovative developments. The same view is shared by the British researchers at New Economic Foundation. They deny the correlation between economic growth, living standards and life quality, highlight the failure of economic growth indicator as a target, because it does not provide an opportunity to determine the distribution of income in a country, to take into account the level of criminality, the level of environmental pollution, the quality and the accessibility of education, medicine and many other important factors.

Indeed, one can note the fact that there is no single theoretical basis that determines the vector of development and the methods of an optimal growth achievement, especially in the context of stagnation. We must also recognize that there is still no common opinion on the form of state development policy both at macro and meso levels.

It is necessary to determine the only categorical apparatus of "growth and development" concepts to substantiate the approach of economy sustainable development choice as one of the tetrads of state management multifactor monitoring within the regional economic system. Quite often they identify these concepts in special literature. For example, it is explicitly stated in [7] "if you do not develop you die". We are against this approach, because the quantitative growth does not mean that qualitative changes take place and the effectiveness of management decisions increases, although it is indisputable that qualitative growth enables a region (an enterprise) to find its own market niche and to function more efficiently. According to the modern economic dictionary, growth should be viewed as the stage of a product life cycle that is characterized by the recognition of consumers, the rapid increase in demand for it, etc. [6].

Different types of growth are distinguished and considered in special literature, including economic, balanced, differentiated, etc.

We consider it is appropriate to address outdated Marxists who formulated the whole scientific concept of development. According to this concept, the development is the universal property of matter, based on general principles and which is the basis of society and cognition development history, the so-called materialistic dialectic.

The features of process development are clearly manifested in a number of laws, including such as the unity and the struggle of opposites, the transition of quantitative transformations into qualitative transformations and negations. More than 100 years ago, V. Lenin formulated the main provisions of development concept of development, in particular, he wrote that development is possible through the prism of "negation through negation" by which the repetition of the occurring processes is meant, but repeating otherwise at the same time. Also, the spiral, spasmodic, catastrophic and revolutionary manifestation of development was not ruled out.

From the position of the development process, the structure of an object can be characterized by three components:

1. The number of components (in this case there may be different structures - binomial, trinomial, n-member ones); 


\section{The order of their location (linear and ring structures);}

3. The nature of dependence (reversible and irreversible structures, the presence of subordination, etc.).

The qualitative nature of current transformations in the course of development lies in the fact that when a structure of one quality passes with its set of parameters to another quality, the parameters (their number, order and interrelations between them) change. This means that the process of development can not be considered merely as the process of a structure amount change for a constituent object, and naturally, it can not be represented as the movement from the structure with $n$ elements to the structure with $n+1$ and $n-1$ element [2]. Hence it is obvious that the development process is characterized by three characteristics: the number of components, the order of their location and the nature of relationship between them.

The fundamental difference of growth concept from the concept of development is easily revealed when it is compared with a living organism. So, for example, the growth process at the cellular level is clearly seen through the increase of cell size by the number of molecules increase. The process of a living organism development is achieved as the result of new compound synthesis, with the development of cells of different types. Obviously, growth implies quantitative changes, and development involves a qualitative change. One has to consider the process of renewal, but not increment as the determining property of growth. In simpler terms, growth appears as an improvement during the development process. Hence, the fundamental difference between growth and development is the availability of qualitative and quantitative characteristics used for the development process, when only a quantitative characteristic is applicable to the growth process.

Let us turn to the concepts of "sustainable development" and economic growth." There is no single representation for each of these concepts here, moreover, there are some works (for example, [3]), whose authors consider the very word combination of sustainable development to be untenable. Indeed, one can agree with the statement that development is a dynamic process, characterized by sharp qualitative leaps, when stability is the static behavior of a system.

The necessity of transition to the winter economy, the application of the interdisciplinary approach, etc. makes it necessary to develop new tools for survival and development strategy planning for regional economic systems. This is impossible without considering the naturally scientific and social-political positions within the unified system of "sustainable development" coordinates.

Researchers recognize that the indicator "the level of economic growth" is untenable during the substantiation, the analysis and the diagnosing of the regional economic system development level, especially in depressed areas where, life expectancy decrease with GDP fall, the increase of student amount, etc. can occur

Unequivocally, the term "growth" assumes the quantitative change in a number of parameters, such as, for example, the volume and the velocity for different flows passing through the economy, while the development is aimed at qualitative improvements in a structure, the structure of physical volumes and flows.

We believe that there is no need to belittle the significance of economic growth theory, since this indicator has been the only indicator for a long time to assess the well-being of population, although, of course, there is a lot of works already that state that it is time to recognize the "end of growth" that demands some alternative sources of human life development.

We have to state that economists have not been able to develop adequate measures for a long time. In general, the followers of economic growth theory say that the search for alternative sources of resources, the renewability of resources, etc. are the starting point of economic growth limit issue solution, which makes the process of substitution theoretically infinite.

In this regard, it is appropriate to present the views of physicists who believe that there is a limit to growth, so that a system limited by this way will come to an end eventually. The monograph "The Limit of Growth" 
(1972), based on the use of the systematic approach to a global problem study, presented mathematical models, some possible scenarios for development were considered and the limited possibilities for economic growth were proved. In particular, such perspectives as population size, industrialization, environmental degradation, food security, the depletion of natural resources, etc. were considered.

The authors concluded that it is expedient to apply a balanced approach that will allow to analyze and diagnose the economic and ecological development trends in order to solve this global problem. We share this approach, because the economy of sustainable development should be a target, and in the sense that it is necessary to focus on life quality improvement, rather than to restrain consumer spending.

We consider it appropriate to present intercountry experience, in particular, German experience. In 2011, the Federal Republic of Germany set up a Commission on Life Growth, Prosperity, and Quality. This commission had to determine the vector of sustainable development and social progress provision, as well as to develop some proper proposals to ensure a new level of life well-being and quality. It is noteworthy that even in such a developed state as Germany, the processes of adoptation and implementation of interagency economy basic trends are difficult to be realized by modern generation. The priority objective of the federal economic policy ("magic square") includes such provisions as sustainable economic growth, a balanced foreign trade balance, low unemployment, low inflation, which causes the criticism of opponents who believe that the concept of economic growth prevails on the concept of sustainable development here.

It should be noted that there is some backwardness, the inhibition of social creation from the current realities almost in all countries. Moreover, one of the modern politicians of Western Europe understands the inconsistency of exponential growth rarely, for which they pay by very inefficient administrative decisions. Thus, in particular, A. Merkel could only increase a working day in Germany trying to solve the problem of unemployment. This decision is extremely ineffective, since it does not take into account the interrelationship between the temporary resource of able-bodied and unemployed consumption process. It is also important that the impact of a working day increase on GDP growth remains a controversial one.

The foregoing confirms the importance of economic growth concept development continuation, which requires to prioritize the issues of monitoring, analysis and the evaluation of quality and living standards, a sustainable and a balanced development of regions, to identify the priority areas for the development of regional social-ecological and economic systems in order to ensure the objectives of ecological and economic balance.

\section{The mechanism of polyfactorial monitoring use as an effective diagnostic apparatus}

In the depressed republics of the North Caucasus, the problems of regional economic system analysis and diagnosis concerning the level of their development, its stability, balance, etc. are particularly relevant nowadays, which requires research, including the problem of a range of interested party determination to create and apply a diagnostic tool for territory sustainable development. The diagnostic system implies instrumental-methodological support, which allows to recognize, identify and evaluate the features, the properties and the state of sustainable and balanced development of a regional social-economic system, taking into account temporal and spatial aspects on the basis of a system approach. It is natural that a range of interested parties at the territories is established by the process of such methodical support tool development, as well as by the processes of its direct application.

The analysis of special literature allows one to assert that the concept of "interested parties" is not mentioned almost by an absolute majority of economists, apparently because they consider this concept is more legal than economic one. Although, the definition of "stakeholders" is quite often used in modern literature in fact, life shows that it is impossible to disclose the essence of social-economic development and the management of territories without the consideration of stakeholders. During the diagnostics of a regional economic system sustainable balanced development, such interested parties (persons) as scientific communities, the public authorities of all levels, experts, performers and press participate. Scientific communities can act both as developers and consumers simultaneously, because, firstly, this community acts as a generator itself, develops the ideology of methodological analysis and diagnostics tool of a territory balanced development; 
secondly, it also acts as an information base consumer, analyzes and improves the toolkit of analysis and diagnostics methodical support for regional economic system development.

The state authorities of all levels can be interested in the initiation of such toolkits of methodical support development and be the consumers of the presented strategic programs for the development of a region. This approach allows them to justify and make the necessary management decisions, compare alternative results, etc.

The relevance and the effectiveness of the device for analysis and diagnosis of a regional economic system development as a tool for self-assessment can be demonstrated by the example of one of the constituent RF entities - the Kabardino-Balkarian Republic. So, according to final result assessment, the activities of RF subject executive authorities, Kabardino-Balkaria Republic ranked as 82d in 2010, 75th in 2011, 73rd in 2012, and almost never received any grants.

Indeed, according to this dynamics, one can characterize the effectiveness of KBR authority activity, their ability to win and maintain a high level of development, etc. rather objectively. Undoubtedly, if the regional authorities were interested to obtain an alternative and a reasoned assessment, if they had the self-assessment tools, then they could achieve a different effectiveness of real governance undoubtedly. Now the republics of the NCFD work to develop new methodological tools at the sectoral ministries, in particular at the Ministry of Economic Development. For this purpose, performing experts are being trained who will be able to collect information and carry out a comprehensive system diagnostics quickly that will allow to provide an objective information about an actual state of regional development indicators [1, 5].

Of course, we must refrain from other extreme thing - the methodological support should not be excessively time-consuming, pseudo-scientific, especially taking into account the lack of qualified personnel and analysts. But it is equally important not to simplify this document.

The growing adaptation of the stakeholder approach to the regional economic system suggests that the level of interaction between different stakeholders does not have a clear vector for a sustainable and a balanced development of the region.

The toolkit for basic component design of a multifactorial monitoring management by regional economic systems consists of a set of unified accounting and analytical and statistical indicators that are structured by the methods of strategic management, which makes it possible to implement the principles of reliability, has a comparative and an adaptive diagnostic tool that, ultimately, allows to realize the check and support functions of management process monitoring for regional social-ecological and economic systems. This approach allows us to establish promptly not only the priority directions for a regional economic system development, but also to identify the problem areas and the mistakes of executive authorities in the field.

Special literature has various models of public administration multifactor monitoring for the regional economic system development, built on cognitive factors of regional development, consisting of four components, as a rule: social, strategic, managerial and target one.

We believe that such models of state management multifactor monitoring concerning the dynamics of regional economic systems do not maintain the principle of economic integrity, because they do not take into account the economic component.

\section{CONCLUSIONS}

The modified polyfactor monitoring of state administration concerning the development of the regional economic system allows us to obtain the system analysis and the diagnostics of the territories, since it takes into account the whole cycle: "goal, resources, technologies, result", combining environment, objects and other components, which also allows us to assess the problems and achievements of the region flexibly and integrally. 
Undoubtedly, the multifactorial monitoring of the state administration by the dynamics of the regional socialecological and economic system development makes it possible to carry out the scientific prediction of the territory development, to reveal potential competitive advantages and to rank the objectives of the state regulation function by the application of direct and indirect influence methods on the system of objects.

The methodical support at this approach allows to formulate the priority directions to implement the regional management stimulation function through the directed influence of the management subject on the socialecological and economic processes of the region through scientifically grounded impact on the diversified objects operating in the region.

The studies of the North Caucasus republic regional policy dynamics make it possible to draw the conclusion about the asymmetry of the targeted programs for regional development, acting as a key factor forming a set of parameters for a multifactor monitoring of the achievement of set goal achievement.

The results of the study can be used by regional authorities during the development of preventive measures to localize and neutralize the problem areas at the local level. Such an approach allows to form an effective operational management locally.

\section{Conflict of interest}

The authors confirm that the presented data do not contain a conflict of interest.

\section{REFERENCES}

Bezirova Z. Kh., Misakov V.S. The analysis of social-ecological and economic development of a subsidized region. Economic sciences. 2011. No. 85. pp. 131-135.

Granberg A.G., Zaitseva Yu.S. Interregional economic comparisons: macroindicators and complex estimates // Bulletin of Russian Humanitarian Scientific Foundation. - 2007. - No. 1 (46). - pp. $41-57$

Gulin K.A., Shabunova A.A., Demenyeva I.N. Public opinion on the economic and political situation in the regions of the north-west of Russia // Public opinion monitoring. - 2007. - №2 (82).

Misakov A.V., Afov H.H. System analysis of information support for the management of single-product enterprises of the regional production facility. The bulletin of Kabardino-Balkarian Scientific Center of the Russian Academy of Sciences. 2010. № 5-1.pp. 75-82.

Misakov V.S., Herter I.K. Criteria and indicators of territory sustainable development. From the collection "The Systemic Crisis in the North Caucasus and the State Strategy for the Macro-regional Development". Proceedings of the All-Russian Scientific Conference. Editor in charge: G.G. Matishov. 2011.pp. 190-193.

Raizberg B.A., Lozovsky L.Sh., Starodubtseva E.B. Modern economic dictionary. - Moscow: INFRA-M, 1996. - 496 p.

Sinyuk T.Yu. The concept of sustainable development as the basis for the diagnosing of the region socialeconomic development // science and business: the ways of development. - 2012. - №5 (11). - pp. 110-117. 